\title{
Direct heat resource assessment and subsurface information systems for geothermal aquifers; the Dutch perspective
}

\author{
L. Kramers ${ }^{1}{ }^{*}$, J.-D. van Wees ${ }^{1,2}$, M.P.D. Pluymaekers ${ }^{1}$, A. Kronimus ${ }^{1}$ \& T. Boxem ${ }^{1}$
}

1 TN0 - Geological Survey of the Netherlands, P.0. Box 80015, 3508 TA Utrecht, the Netherlands.

2 Utrecht University, Faculty of Geosciences, P.0. Box 80021, 3508 TA Utrecht, the Netherlands.

* Corresponding author. Email: leslie.kramers@tno.nl.

Manuscript received: Jan 2012, accepted: May 2012

\begin{abstract}
A resource assessment methodology has been developed to designate prospective high permeable clastic aquifers and to assess the amount of potential geothermal energy in the Netherlands. It builds from the wealth of deep subsurface data from oil and gas exploration and production which is publicly and digitally available. In the resource assessment various performance indicator maps have been produced for direct heat applications (greenhouse and spatial heating). These maps are based on detailed mapping of depth, thickness, porosity, permeability, temperature and transmissivity (methodology presented in other papers in this NJG issue). In the resource assessment analysis 14 lithostratigraphic units (clastic aquifers) have been considered, ranging in age from the Permian to the Cenozoic. Performance maps have been made which include a) the expected doublet power (MWth) to be retrieved; b) the number of houses or hectares that can be heated from one doublet; and c) a potential indicator map, which provides insight in subsurface suitability for specific applications from a techno-economic perspective. To obtain a nationwide overview of the resource potential in terms of recoverable geothermal energy, a progressive filtering approach was used from total heat content of the reservoirs (Heat In Place - HIP) via the heat that can potentially be recovered (Potential Recovery Heat - PRH) to energy maps taking into account a techno-economic performance evaluation (Recoverable Heat - RH). Results show that the HIP is approximately 820,000 PJ which is significantly more than previous estimates of around 90,000 PJ. This considerable increase in geothermal energy potential is the result of accurate geological mapping of key reservoir properties and the development of state-of-the-art techno-economic performance assessment tools that performs Monte Carlo simulation. Moreover, for the previous estimates boundary conditions were set with the aim to compare the geothermal potential between different EU countries (Rijkers \& Van Doorn, 1997). Taking into account techno-economic aspects, the RH is in the order of $85,000 \mathrm{PJ}$. This is equivalent to $70 \%$ of the ultimate recoverable gas of the Slochteren Gas field. In total over 400 maps have been created or used as input for the resource assessment. Together, they provide comprehensive information for geothermal energy development from various stakeholder perspectives. The maps can be interactively assessed in the web-based portal ThermoGIS (www.thermogis.nl). This application complements existing subsurface information systems available in the Netherlands and supports the geothermal community in assessing the feasibility of a geothermal system on a regional scale.
\end{abstract}

Keywords: Direct geothermal heat, geothermal potential, geothermal energy, geological mapping, geothermal maps, information systems, prospective aquifers, resource assessment, techno-economic performance assessment, ThermoGIS, resource potential maps, Quick scan tool, web-based information system

\section{Introduction}

In the 1980s, several inventory studies were carried out by the Geological Survey (RGD) to explore the potential of geothermal resources in the Netherlands. The first geothermal well in the Netherlands was drilled in 1987 near Asten in the province of
Noord-Brabant. Unfortunately, the performance was below expectations and the well was closed in. Activities in geothermal energy research more or less ceased afterwards.

As a consequence of dramatic increase in oil prices in the last decade, geothermal energy gained renewed interest. In 2007, a horticulturist in Bleiswijk was the first to successfully 
produce hot water from the deep subsurface in the Netherlands. At present, this horticulturist is heating 14 ha of greenhouses from two doublets. Following this success, interest in geothermal energy spectacularly increased. To date, nearly 100 exploration licenses for geothermal resources have been granted by the Ministry of Economic Affairs, Agriculture and Innovation (EL\&I; Fig. 1).

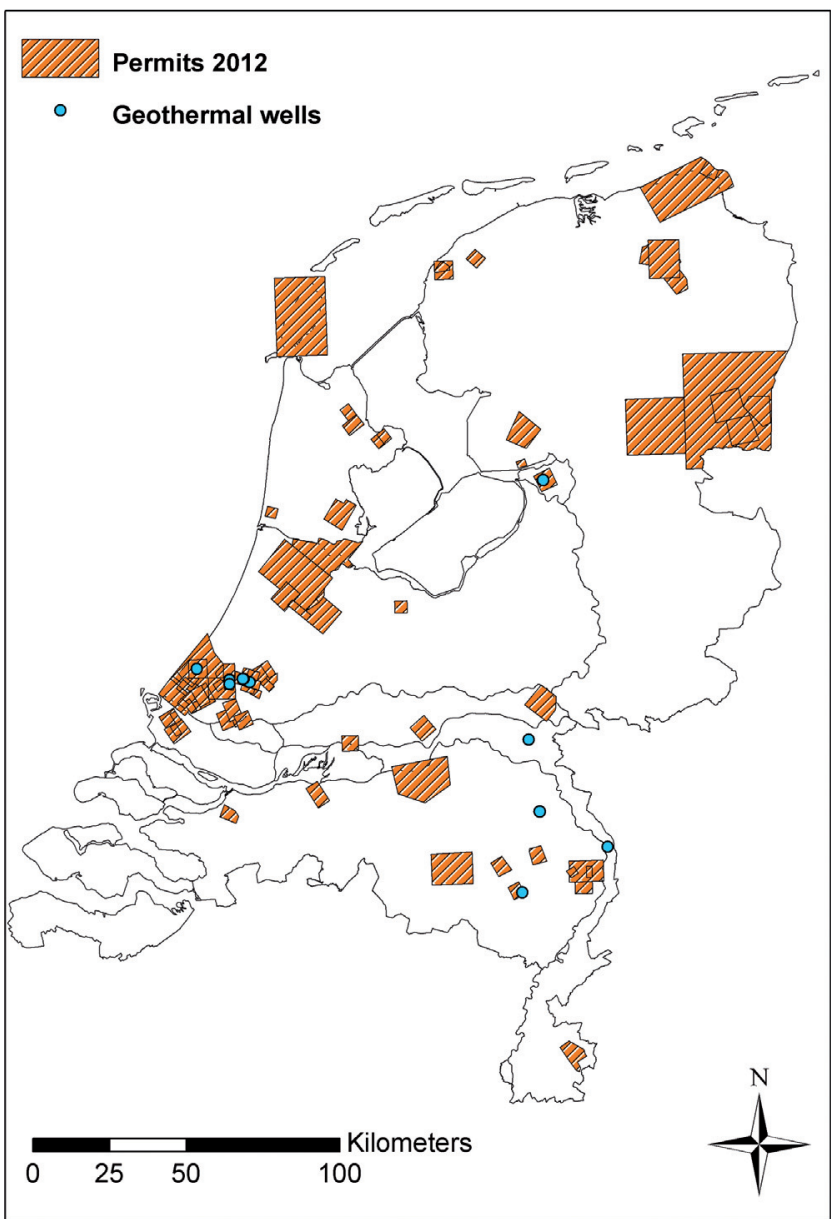

Fig. 1. Overview of geothermal wells and current (exploration) permits which are granted or on request.

Compared to other countries in Europe, the Netherlands is in a unique position as it is densely covered by exploration and production wells from the oil and gas industry. This includes over 5000 deep wells, extensive 3D seismic coverage (60\%) and over 150,000 core-plug measurements. Geothermal exploration can strongly benefit from this wealth of available data especially as prospective geothermal areas largely overlap with areas of hydrocarbon exploration. In the Netherlands, these data are freely accessible at the Digital Information portal of the Dutch Subsurface (www.dinoloket.nl) and the Dutch 0il and Gas portal Data (www.nlog.nl).

The large amount of data available to the geothermal community can be effectively utilised to locate potential geothermal 'hot spots'. To governmental bodies, such as geological surveys, it is however a challenge to comply with the varying backgrounds of stakeholders and to facilitate them accordingly. Until recently, these data and access to the data has not been tailored to the needs of stakeholders in geothermal development. In order to improve the access to relevant subsurface information and to visualise prospective geothermal areas, TNO has developed a dedicated 3D web-based information system named ThermoGIS. ThermoGIS provides a first quick scan, based on regional interpretations of the subsurface, prior to more indepth geological and economic feasibility studies necessary for further development (Fig. 2). The development of ThermoGIS comprised two major phases. During phase one the depth, thickness, permeability and temperature of potential reservoirs were mapped on a regional scale. The methodology and results of this work are presented in Pluymaekers et al. (this issue) and Bonté et al. (this issue). The next step included the development of resource potential maps. The reader is referred to Van Wees et al. (this issue) for more detailed information about the techno-economic performance tool.

This paper presents the results of the resource assessment and the web-based information system (www.thermogis.nl). First, the methodology for estimating resource potential of geothermal aquifers in a mature oil and gas province is described. Secondly, the key results for the geothermal resource potential maps are presented. Finally the information system features are briefly summarised.

\section{Methodology for estimating geothermal resource potential of aquifers in a mature oil and gas province}

The regional resource assessment has two aims; one is to obtain a map-based overview of prospective regions for geothermal direct heat applications and the second is to obtain an estimate for the amount of geothermal energy which can be extracted from the subsurface. The results presented in this paper were applied to both greenhouses and spatial heating (Table 1).

Prior to the computation of the geothermal resource potential, prospective geothermal aquifers have been selected using well data and literature based on the following criteria (see also Pluymaekers et al., this issue): 1) distribution over a large area; 2) the water temperature should be at least $40{ }^{\circ} \mathrm{C}$; and 3) an aquifer should have a minimum thickness and transmissivity. In total 20 aquifers have been selected (Table 2). For each of these aquifers, the key hydrological properties were mapped and the uncertainties were assessed (see Pluymaekers et al., this issue). Subsequently, all Permian (Rotliegend) aquifers were combined to compute one value of performance and associated resource potential. The same procedure was applied to the Triassic, Jurassic, Cretaceous and Cenozoic aquifers. Table 3 gives an overview of the resulting resource maps.

In order to produce resource potential maps, geological properties (temperature, permeability and thickness) were used 


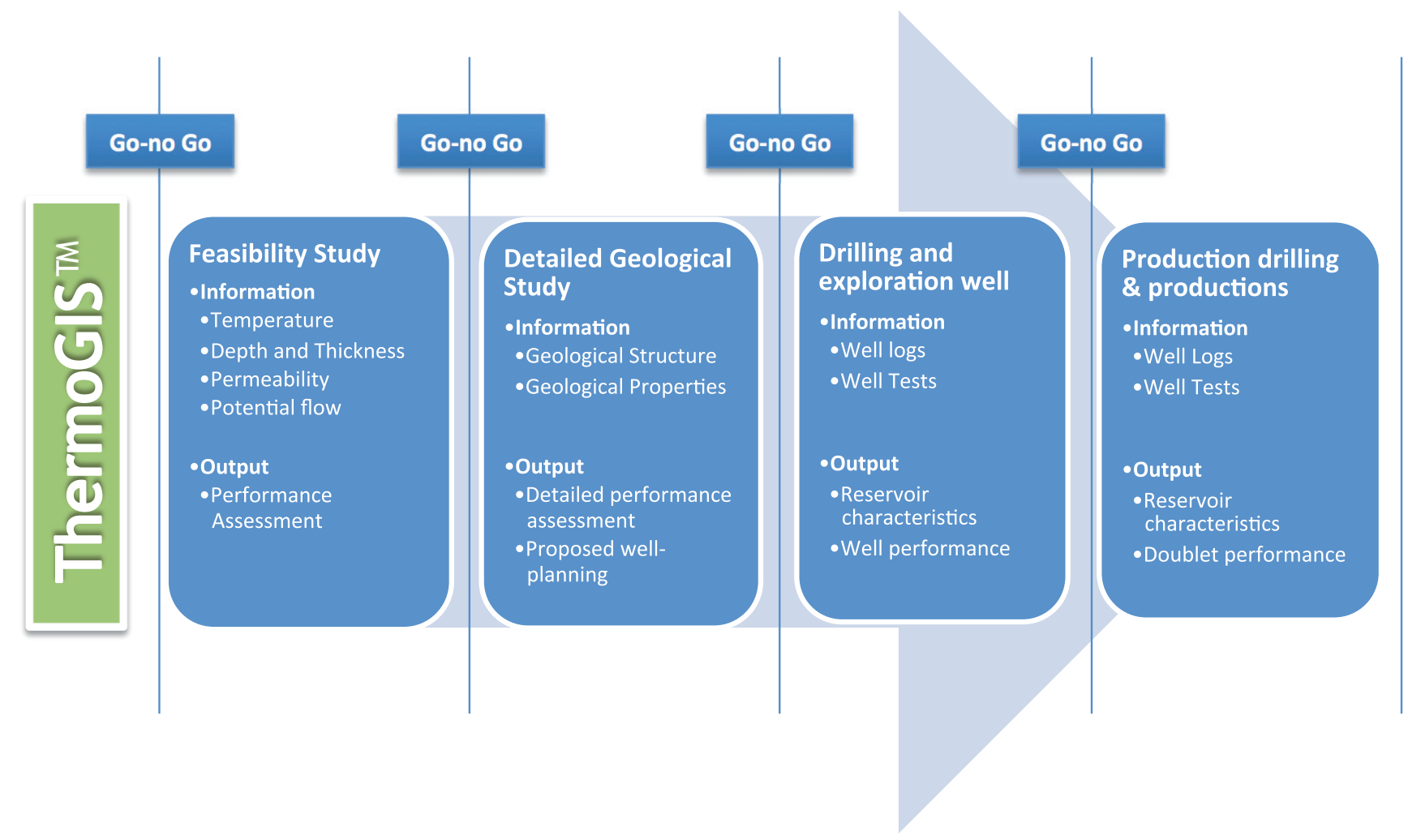

Fig. 2. A common development scheme from first intention towards implementation of a geothermal system. Before starting with a feasibility study it is worthwhile to have a first impression of the geothermal potential of an area. An information system or quick scan tool like ThermoGIS can fulfil this need.

as input in a batch mode edition of DoubletCalc to obtain doublet performance figures at a spatial resolution of $500 \mathrm{~m}$ (for details see Van Wees et al., this issue). Calculation results include technical and economic key performance indicators such as doublet geothermal power, required pump power, volume and mass flows, the Coefficient Of Performance (COP) and Levelised Costs of Energy (LCOE in $€ / G J)$. DoubletCalc performance calculations have been carried out for P10, P30, P50, P70 and P90 values of transmissivity (average permeability times thickness of the aquifer). Uncertainties in temperature, depth and well engineering properties were neglected because the influence on performance is an order of magnitude lower than the uncertainty in transmissivity.

For both application types (greenhouse and spatial heating) the $\mathrm{COP}$ is set at a target level of 15 . The COP specifies the ratio of the geothermal power and the electric power consumption

Table 1. Generalised direct heat application production characteristics used in this study (after Van Wees et al., this issue). The load factor specifies the amount of operational hours in a year relative to the total amount of hours in a year.

\begin{tabular}{llll}
\hline $\begin{array}{l}\text { Geothermal direct } \\
\text { heat application }\end{array}$ & $\begin{array}{l}\text { Minimum } \\
\text { production } \\
\text { temperature }\end{array}$ & $\begin{array}{l}\text { Minimum } \\
\text { production } \\
\text { depth @ 30 } 30^{\circ} \mathrm{C} / \mathrm{km}\end{array}$ & $\begin{array}{l}\text { Re-injection } \\
\text { temperature }\end{array}$ \\
\hline Spatial & $45^{\circ} \mathrm{C}$ & $1200 \mathrm{~m}$ & $25^{\circ} \mathrm{C}$ \\
Greenhouse & $65{ }^{\circ} \mathrm{C}$ & $1900 \mathrm{~m}$ & $40^{\circ} \mathrm{C}$ \\
\hline
\end{tabular}

of the pumps. A COP of 15 is generally considered as a lower limit. The results of the $\mathrm{P} 10-\mathrm{P} 90$ calculations have been used to determine greenhouse and spatial heating overviews for each aquifer.

\section{Maps to identify prospective areas}

\section{Doublet Power map (MWth)}

The Doublet Power Map (Fig. 3) gives an indication of the expected power retrieved by a doublet. It has been compiled from the P30 and P50 maps of power calculations using DoubletCalc. The compilation takes the P50 map as input, replacing P50 values with P30 values when predicted power is lower than 10 MWth. The resulting map has been subdivided in three power potential classes: 1) unknown; 2) possible power potential >10 MWth; and 3) good power potential >10 MWth. The class 'unknown' corresponds to a probability of less than $30 \%$ that an aquifer is present and is going to produce 10 MWth. The class 'possible power potential' corresponds to a probability of at least $30 \%$ that the aquifer is capable to produce $10 \mathrm{MWth}$ or more. The other class corresponds to a $50 \%$ probability that the aquifer is capable to produce 10 MWth or more. Local and more specific studies may however reduce geological uncertainty and optimise engineering parameters. 
Table 2. List of prospective aquifers that is included in ThermoGIS. For details on the mapping of aquifer properties and underlying uncertainties see Pluymaekers et al. (this issue).

\begin{tabular}{|c|c|c|c|c|c|}
\hline Stratigraphic unit & Stratigraphic Group & $\begin{array}{l}\text { ThermoGIS } \\
\text { group code }\end{array}$ & $\begin{array}{l}\text { Stratigraphic } \\
\text { Formation }\end{array}$ & Stratigraphic Member & $\begin{array}{l}\text { ThermoGIS } \\
\text { member code }\end{array}$ \\
\hline \multirow[t]{8}{*}{ North Sea } & Lower North Sea & $\mathrm{N}$ & Veldhoven & Voort & NMVFV \\
\hline & & & Rupel & Steensel & NMRFT \\
\hline & & & & Vessem & NMRFV \\
\hline & & & Dongen & Basal Dongen Sand & NLFFD \\
\hline & & & Landen & Reusel & NLLFR \\
\hline & & & & Heers Sand & NLLFS \\
\hline & & & & Swalmen & NLLFL \\
\hline & & & & $\begin{array}{l}\text { Swalmen, Heers Sand, Reusel, Basal Dongen Sand, } \\
\text { Vessem, Steensel, Voort }\end{array}$ & N-Stacked \\
\hline \multirow[t]{5}{*}{ Lower Cretaceous } & Rijnland & KN & Vlieland Sst. & Friesland Sst. & KNNSF \\
\hline & & & & Gildehaus Sst. & KNNSG \\
\hline & & & & Bentheim Sst. & KNNSP \\
\hline & & & & Rijswijk Sst., Berkel Sst., IJsselmonde Sst., & KNWNB \\
\hline & & & & De Lier Sst. stacked & \\
\hline \multirow[t]{2}{*}{ Jurassic } & Schieland & S & Nieuwerkerk & Delft Sst. & SLDND \\
\hline & & & & Jurassic \& Lower Cretaceous & JK-Stacked \\
\hline \multirow[t]{9}{*}{ Triassic } & Upper Germanic Triassic & TR & Röt & Röt Fringe Sst. & RNROF \\
\hline & Lower Germanic Triassic & & Hardegsen & & RBMH \\
\hline & & & Detfurth & Upper Detfurth Sst. & RBMDU \\
\hline & & & & Lower Detfurth Sst. & RBMDL \\
\hline & & & Volpriehausen & Upper Volpriehausen Sst. & RBMVU \\
\hline & & & & Lower Volpriehausen Sst. & RBMVL \\
\hline & & & & Lower Volpriehausen Sst., Upper & TR-Stacked \\
\hline & & & & Volpriehausen Sst., Lower Detfurth Sst., & \\
\hline & & & & Upper Detfurth Sst., Hardegsen Fm., Röt Fringe Sst. & \\
\hline \multirow[t]{3}{*}{ Permian } & Upper Rotliegend & RO & Slochteren & (Upper) Slochteren & ROSLU \& ROSL \\
\hline & & & & Lower Slochteren & ROSLL \\
\hline & & & & (Upper) Slochteren and Lower Slochteren & R0-Stacked \\
\hline
\end{tabular}

Table 3. Performance assessment maps for each aquifer and base maps.

\begin{tabular}{|c|c|c|}
\hline \multicolumn{3}{|l|}{ Performance } \\
\hline Potential & Good, possible, unknown & $\begin{array}{l}\text { Maps indication the probability of economic success designated in classes 'unknown', possible } \\
\text { and good potential }\end{array}$ \\
\hline Power & MWth & $\begin{array}{l}\text { Indication about the potential performance based on classes 'unknown, possible } 10 \text { MWth, good } \\
\text { potential for }>10 \mathrm{MW}_{\mathrm{th}}>15 \mathrm{MWth} \& 20 \mathrm{MWth}\end{array}$ \\
\hline Heat In Place & $\mathrm{PJ} / \mathrm{km}^{2}$ & Map showing the maximum theoretically extractable heat \\
\hline Technical potential & $\mathrm{PJ} / \mathrm{km}^{2} / \mathrm{yr}$ & $\begin{array}{l}\text { The heat which can be recovered from the reservoir unconstrained by techno-economic } \\
\text { limitations irrespective of flow properties }\end{array}$ \\
\hline Application scale & $\begin{array}{l}\text { \# of houses or hectares } \\
\text { greenhouse }\end{array}$ & $\begin{array}{l}\text { Maps showing the number of hectares greenhouse based on the Technical potential } \\
\text { greenhouse or houses }(\times 1000)\end{array}$ \\
\hline \multicolumn{3}{|l|}{ General } \\
\hline Municipalities & & Map of all (small) villages and cities \\
\hline Provinces & & Map of borders provinces \\
\hline Permits & & Current status of granted or \\
\hline Wells & & Location of production and exploration wells \\
\hline Gas/oil fields & & Polygon map of gas and oil fields \\
\hline
\end{tabular}




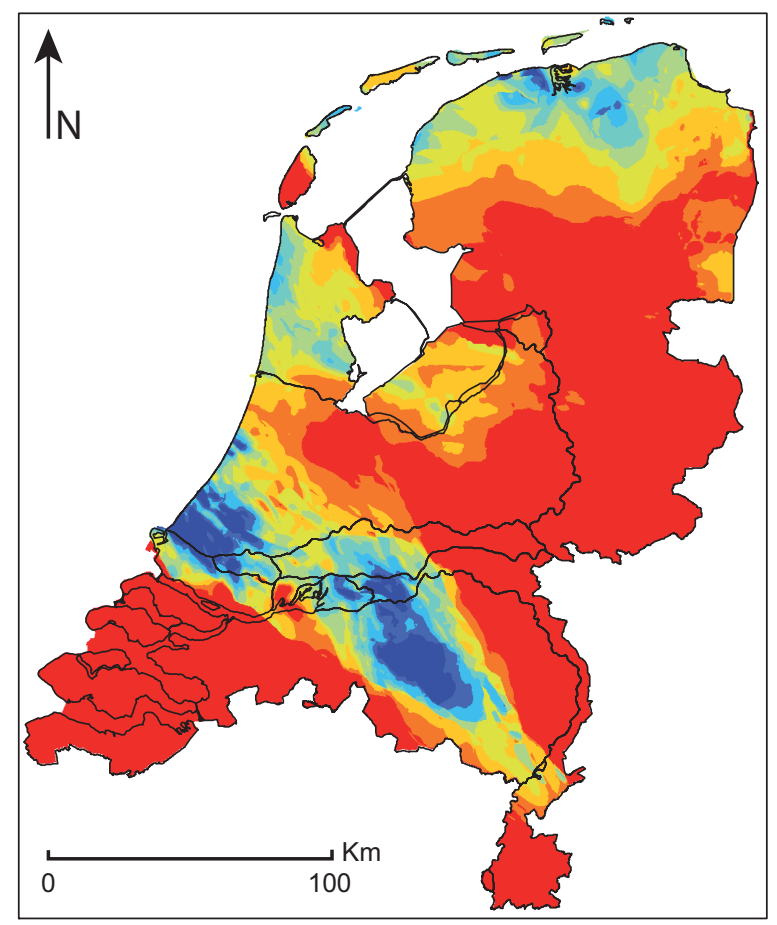

Technical Potential $\left(\mathrm{PJ} / \mathrm{km}^{2} / \mathrm{y}\right)$

\begin{tabular}{|l|l|l|}
\hline $0-0.1$ & $0.3-0.4$ & $0.6-0.7$ \\
\hline $0.1-0.2$ & $0.4-0.5$ & $0.7-0.8$ \\
$0.2-0.3$ & $0.5-0.6$ & $0.8-0.9$ \\
\hline
\end{tabular}

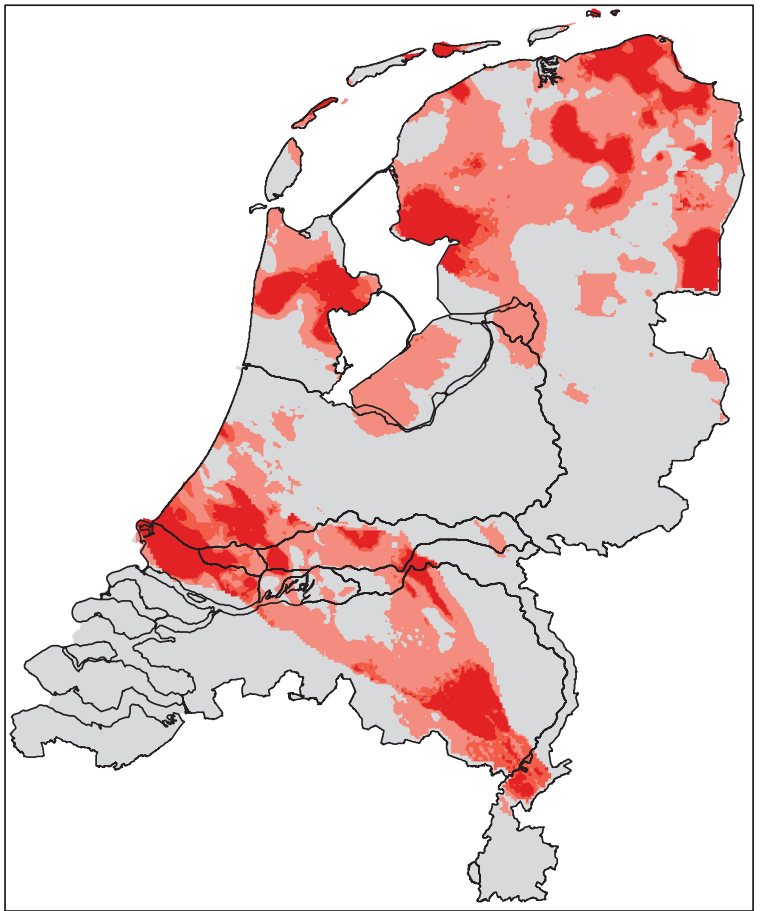

Application scale (acres greenhouse)

Unknown

$0-16$

$16-24$

$24-32$

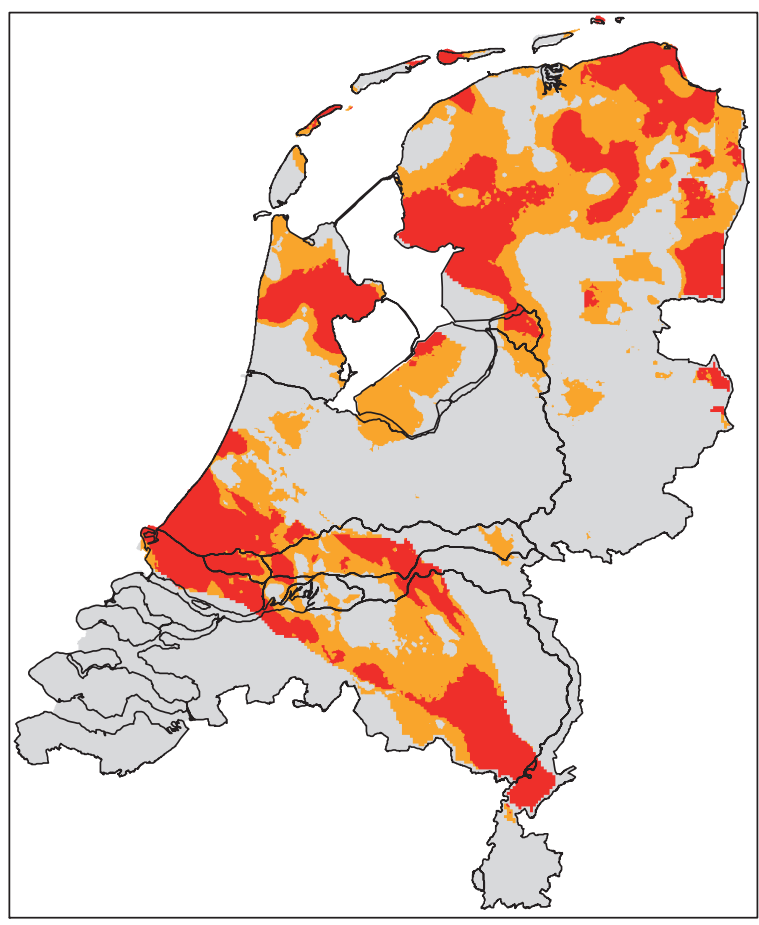

Geothermal potential

\section{Unknown \\ Possible potential \\ Good potential}
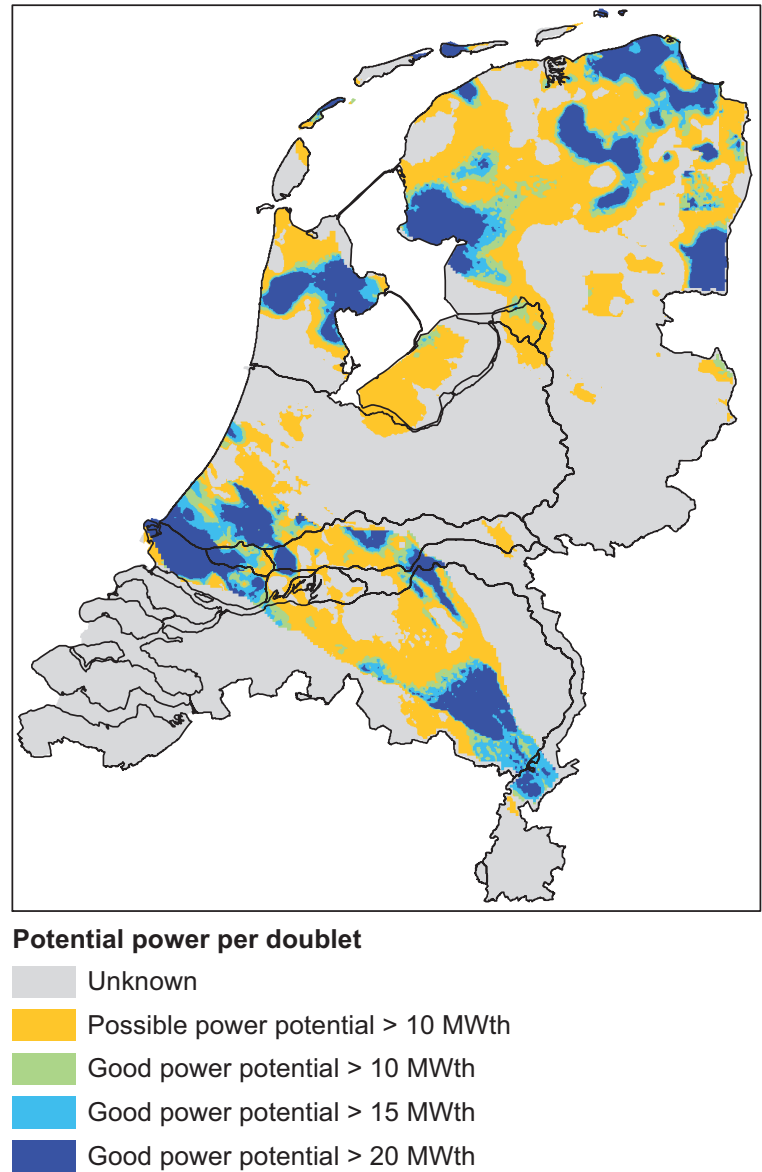

Fig. 3. Upper left; technical potential of all mapped aquifers in $\mathrm{PJ} / \mathrm{km}^{2} / \mathrm{yr}$, upper right; geothermal potential, lower left; application scale in hectares greenhouse and lower right; the potential power per doublet. All figures shown here are computed for greenhouse heating. 


\section{Application scale map (1000 houses and hectares per doublet)}

The application scale indicates the number of houses (spatial heating) or acres (greenhouses) that can be heated utilising geothermal energy (Fig. 3). The results are based on the predicted doublet power, the load factor (the ratio of yearly load hours and total hours in a year) and the yearly heat demand.

\section{Potential map}

The potential map (Fig. 3) gives an overview of the subsurface suitability for a specific application. It has been compiled from the P30 and P50 maps of the predicted power where it can be produced economically ( $\mathrm{LCOE}<6 € / \mathrm{GJ}$ ). Initially the P50 map is used; in case the predicted power is less than 10 MWth or $\mathrm{LCOE}>6 € / \mathrm{GJ}$ the $\mathrm{P} 50$ values will be replaced by $\mathrm{P} 30$ values. The resulting map has been subdivided in three potential classes: 1) unknown; 2) possible potential; and 3) good potential. The class 'unknown' corresponds to less than $30 \%$ probability that the aquifer is capable to develop an economic project. The classes 'possible potential' and 'good potential' designate areas were there is more than respectively $30 \%$ and $50 \%$ probability that an aquifer permits an economic project. We also tested higher cut-off levels for LCOE. These slightly increase the boundaries of the classes, but not significantly as the expected transmissivity (P50, P30) has large spatial variation and strongly controls the performance. The probability ranges are determined on the basis of the regional maps and the transmissivity maps. More details about the approach in creating these probablity maps are presented in Pluymaekers et al., 2012. More detailed studies reducing uncertainty and optimising engineering parameters for local circumstances should further de-risk predictions.

\section{Resource potential maps}

The aforementioned maps serve to highlight prospective areas. These maps relate to the performance of the doublets, but cannot be used to determine the geothermal resource potential in the subsurface. Resource potential has been calculated at different levels of technical and economic confidence and is explained briefly below. It builds from a progressive filtering approach in a capacity pyramid (Fig. 4) starting from the heat available in aquifers.

\section{Heat In Place $\left(P J / \mathrm{km}^{2}\right)$}

Starting point at the base of the pyramid is Heat in Place (HIP) in $\mathrm{PJ} / \mathrm{km}^{2}$. This is the heat content of the reservoir (cf. Muffler \& Cataldi, 1978). The HIP is the maximum theoretically extractable heat in the aquifer.

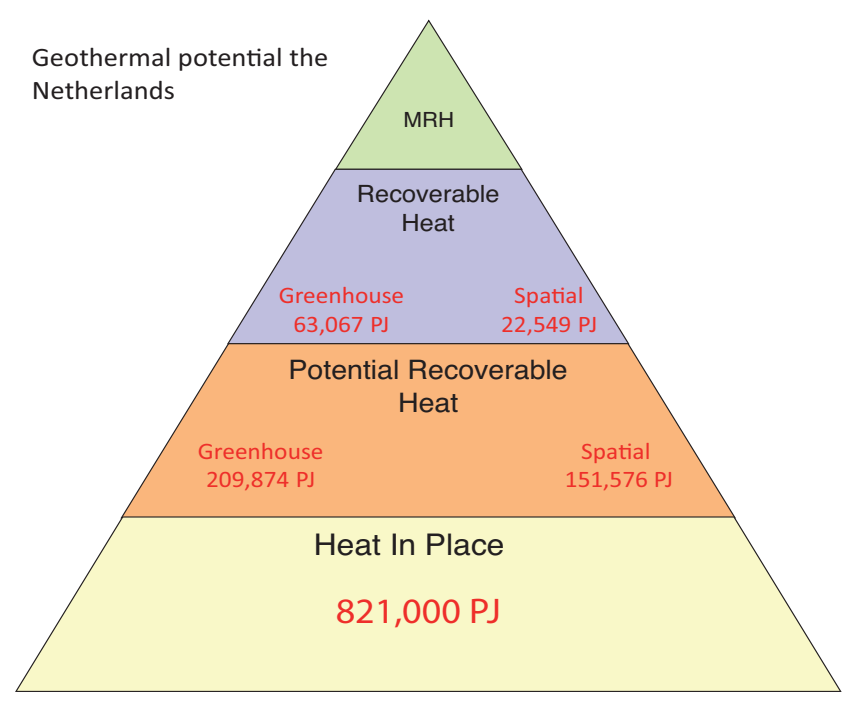

Fig. 4. Filtering pyramid showing the total heat content for $R H$ (Recoverable Heat), PRH (Potential Recoverable Heat) and HIP (Heat in Place).

$$
\text { HIP }=\gamma\left(T_{\text {res }}-T_{\text {sur }}\right) h \quad \text { Where } \mathrm{V}=\Phi\left(C_{\mathrm{w}} \cdot \rho_{\mathrm{w}}+(1-\Phi) \mathrm{C}_{\mathrm{r}} \cdot \rho_{\mathrm{W}}\right.
$$

$\mathrm{Y}=$ Total heat capacity $\left(\mathrm{GJ} / \mathrm{m}^{2}\right)$

$\mathrm{T}_{\text {res }}=$ Reservoir temperature $\left({ }^{\circ} \mathrm{C}\right)$

$\mathrm{T}_{\text {sur }}=$ Avearge surface temperature $\left({ }^{\circ} \mathrm{C}\right)$

$\mathrm{h}=$ thickness $(\mathrm{m})$

$\Phi=$ Porosity (-)

$\mathrm{C}_{\mathrm{w}}=$ Heat capacity water $\left(\mathrm{J} / \mathrm{kg}{ }^{\circ} \mathrm{C}\right)$

$\rho_{\mathrm{W}}=$ Water density $\left(\mathrm{kg} / \mathrm{m}^{3}\right)$

$\mathrm{C}_{\mathrm{r}} \quad=$ Heat capacity reservoir $\left(\mathrm{J} / \mathrm{kg}^{\circ} \mathrm{C}\right)$

Potential Recoverable Heat $\left(P J / \mathrm{km}^{2}\right)$ and Technical potential (PRH/30 yr)

The next level of the pyramid is the Potential Recoverable Heat (PRH). This is the heat which can be extracted from the reservoir, unconstrained by economic limitations and irrespective of flow properties. Following Van Wees et al. (this issue) the recoverable heat is about $33 \%$ of the HIP. The technical lifetime of a doublet is 30 years. Consequently the maximum yearly recoverable heat, unconstrained by economics is $\mathrm{PRH} / 30$. This figure (Fig. 3) is useful for matching heat demand maps (e.g. Warmteatlas Nederland, 2012) with potential geothermal heat supply areas.

\section{Recoverable Heat $\left(\mathrm{PJ} / \mathrm{km}^{2}\right)$}

The Recoverable Heat map (RH) has been calculated from PRH taking into account a DoubletCalc performance evaluation. The areas with recoverable heat within and beyond the $\mathrm{P} 30$ and P50 ranges of transmissivity correspond to areas of 'possible potential' and 'good potential'. The volume of rock in $\mathrm{RH}$ is therefore a subset of PRH. 


\section{Geothermal resource potential in the Netherlands}

Prospective geothermal resources are located mainly in the north and south of the Netherlands. Based on the resource assessment results the $\mathrm{RH}$ can be transferred to potential power per doublet or application scale (hectares of greenhouse or number of houses). Figure 4 depicts the different resource assessment maps of all aquifers for greenhouses. Similar maps have been made for spatial heating.

The total HIP of all prospective aquifers is more than $820,000 \mathrm{PJ}$. The PRH is in the order of 209,000 PJ and 150,000 PJ for greenhouses and spatial heating respectively, while the $\mathrm{RH}$ is in the order of $63,000 \mathrm{PJ}$ and 22,500 PJ respectively (Fig. 4). This RH figure equals the present-day energy consumption of all Dutch greenhouses (about 10,000 ha) for at least 500 years (assuming a heat demand of $12,000 \mathrm{GJ} / \mathrm{ha} / \mathrm{yr}$ ). The 22,500 PJ available for spatial heating implies that 1 million houses can be heated for almost a 1000 years, assuming $25 \mathrm{GJ} / \mathrm{yr}$ per house and effective use of all available RH. Numbers for each geological group are summarised in Table 4. Fluctuations in gas price and improved (less expensive) drilling techniques will have effect on the amount of Recoverable Heat and will therefore change through time.

\section{Geothermal potential in stacked Cenozoic aquifer members}

The Cenozoic North Sea Group is mainly a sequence of (unconsolidated) clay- and sand layers. With the exception of the south-eastern part of the Netherlands most of the Cenozoic aquifers are too shallow (less then $1000 \mathrm{~m}$ depth) to have an appropriate temperature for conventional geothermal systems. In addition, the potential of individual sandstone layers is likely to be insufficient because of a low transmissivity. However, production from multiple sand layers simultaneously might still result in an economic flow rate (Fig. 5).

The total HIP for the mapped Cenozoic aquifers is approximately 55,000 PJ. Taking into account technical and economical aspects, about $1100 \mathrm{PJ}$ of energy is available for heating greenhouses (Table 4). As temperatures do not exceed $60^{\circ} \mathrm{C}$, Cenozoic geothermal resources seem to be less suitable for district heating.

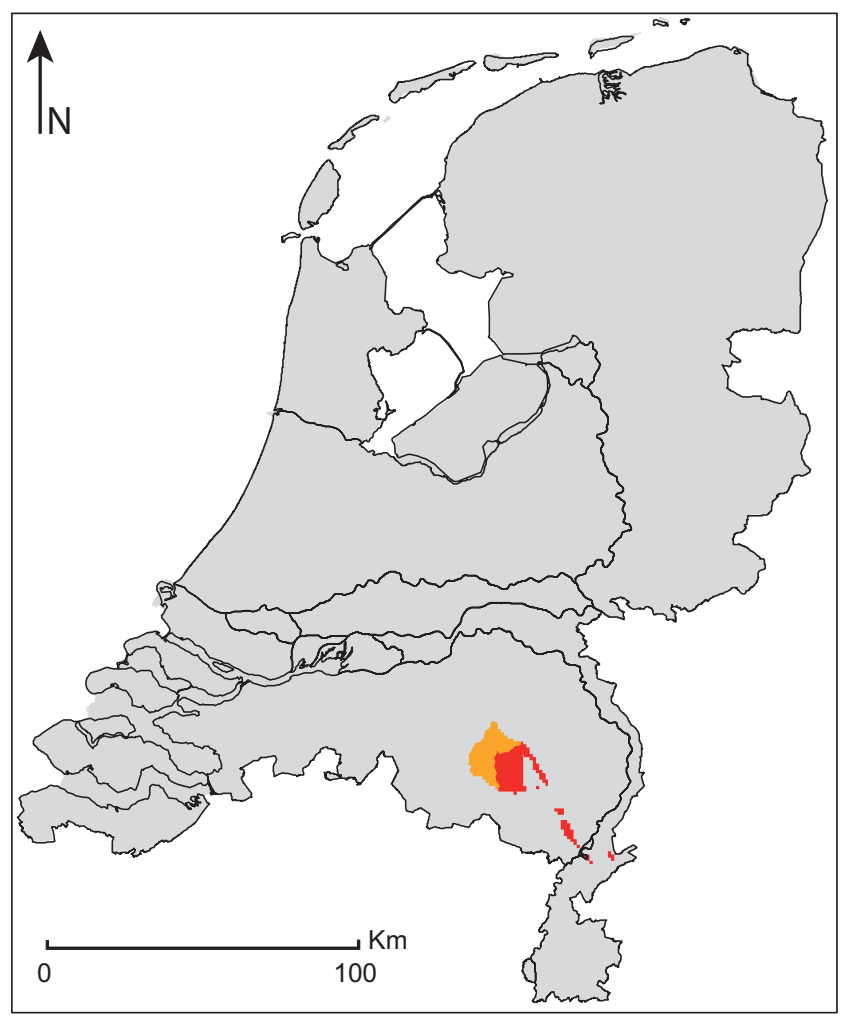

Geothermal potential greenhouse

Unknown
Possible potential
Good potential

Fig. 5. Potential for greenhouse heating in the Cenozoic Lower and Middle North Sea Groups. These aquifers are at relative shallow depth, which explains the low geothermal potential of these geological groups (assuming that temperatures of at least $40^{\circ} \mathrm{C}$ are needed for a successful doublet).

\section{Geothermal potential in the stacked Lower Cretaceous and Jurassic aquifer members}

The sandstone members of the Lower Cretaceous are predominantly located in the West Netherlands Basin (WNB) in the west of the Netherlands (Fig. 6). The Delft Sandstone Member (belonging to the Jurassic Schieland Group) is also present in the WNB. It has to be noted that maps of the Delft Sandstone Member are very preliminary, related to poor imaging of the succession.

Table 4. Estimated geothermal energy potential for the stratigraphic units. Members within each stratigraphic groups have been stacked.

\begin{tabular}{|c|c|c|c|c|c|c|}
\hline & \multirow{3}{*}{$\frac{\text { Lokhorst \& Wong (2007) }}{\text { HIP }}$} & \multicolumn{5}{|c|}{ ThermoGIS } \\
\hline & & \multirow[t]{2}{*}{ HIP } & \multicolumn{2}{|l|}{ PRH } & \multicolumn{2}{|l|}{ RH } \\
\hline & & & Greenhouse & Spatial & Greenhouse & Spatial \\
\hline Upper Rotliegend Sandstones & 50,000 & 409,000 & 111,244 & 84,694 & 27,626 & 11,897 \\
\hline Triassic Sandstones & 37,000 & 305,000 & 82,422 & 61,515 & 25,877 & 9,577 \\
\hline Lower Cretaceous and Jurassic Sandstones & 3,400 & 52,000 & 12,512 & 5,367 & 8,417 & 1,075 \\
\hline Cenozoic Sandstones & 0 & 55,000 & 3,696 & 0 & 1,147 & 0 \\
\hline Total HIP & 90,400 & 821,000 & & & & \\
\hline
\end{tabular}




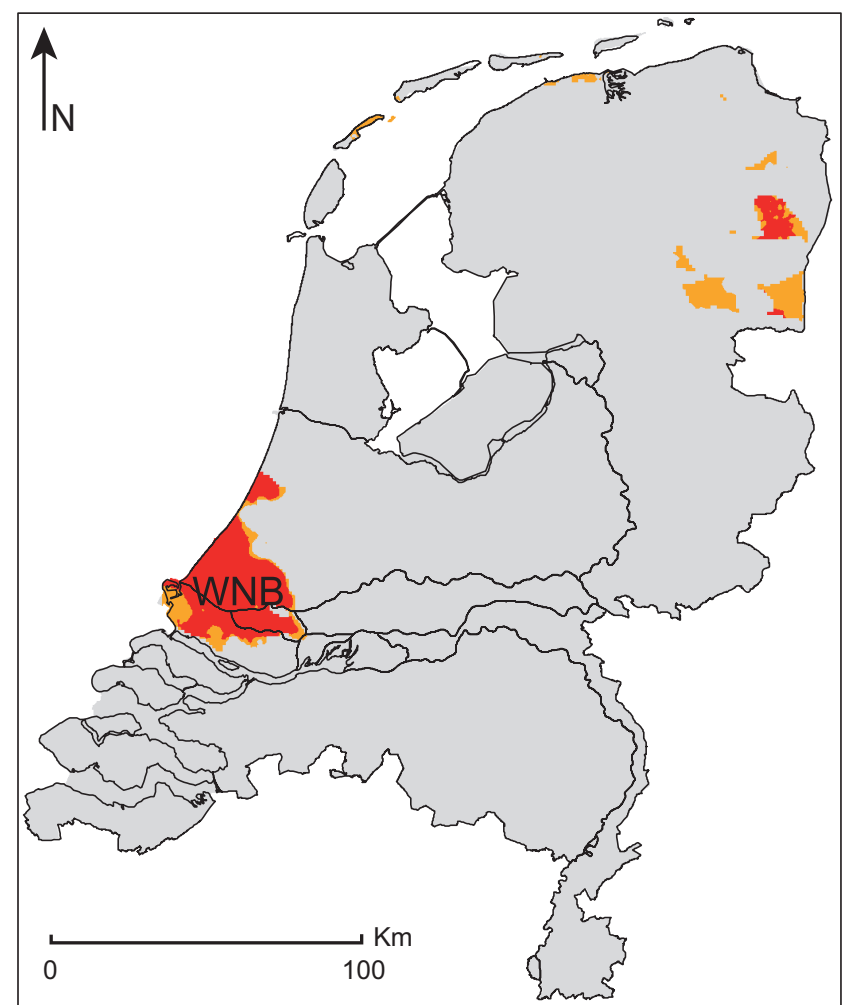

Geothermal potential greenhouse

Unknown

Possible potential

Good potential

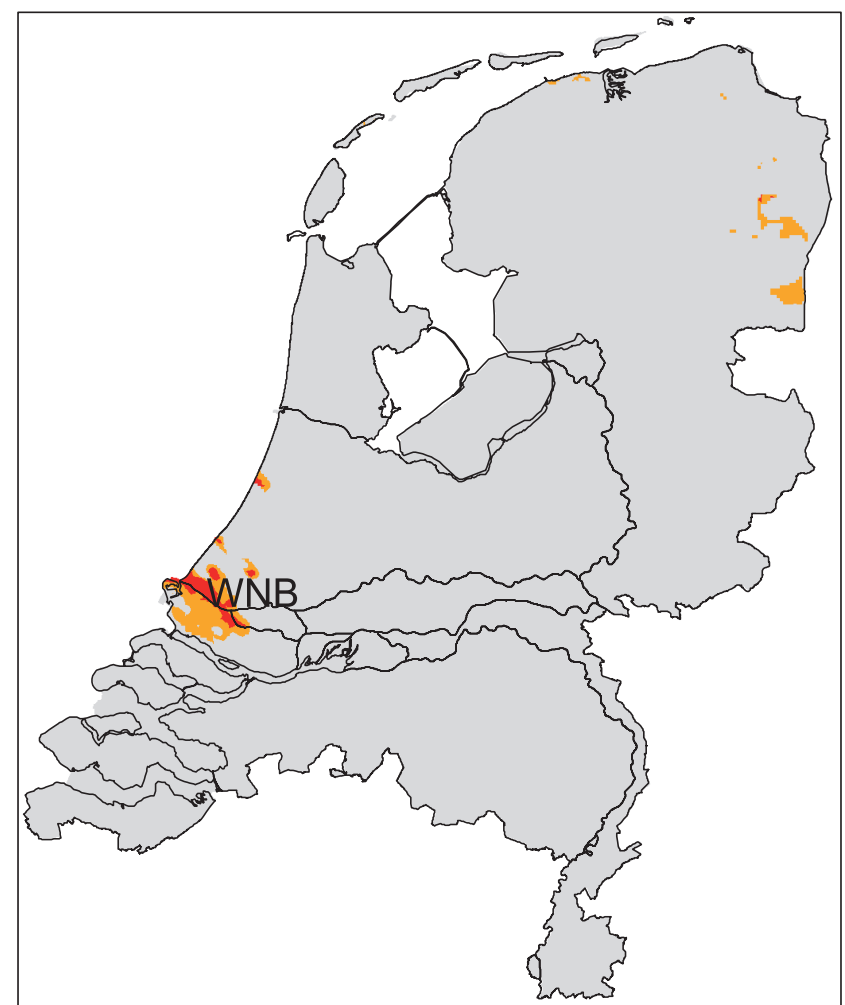

Geothermal potential spatial

Unknown

Possible potential

Good potential

Fig. 6. Potential areas in the Lower Cretaceous Rijnland and Jurassic Schieland Groups. Potential areas for greenhouses on the right, for spatial heating on the left.

The HIP of the Lower Cretaceous and Jurassic aquifers for greenhouse and spatial heating are ca 53,000 PJ and 35,000 PJ respectively. Temperature conditions may favor greenhouse heating ( $\mathrm{RH}$ is about $8400 \mathrm{PJ}$ ) whilst the deeper aquifers of both groups may also allow spatial heating as temperature conditions are more sufficient than the relatively shallow aquifers. The PRH for spatial heating is in the order of $5400 \mathrm{PJ}$ (Table 4).

So far, five doublets producing heat from Lower Cretaceous or Late Jurassic reservoirs have been realised in the WNB. Many new doublets may follow regarding the present-day geothermal exploration activities. In the southern part of the WNB reservoir conditions also permit spatial heating. At present one doublet is realised in The Hague which will extract water from the Delft Sandstone Mb. The doublet awaits fitting to the district heating network.

The WNB is prospective in terms of oil and gas. Hydrocarbons have been trapped in the same sandstones as those interesting for geothermal energy. Some of the realised geothermal doublets did find minor quantities of residual hydrocarbons. This requires additional investments in order to separate the hydrocarbons from the water. After separation the hydrocarbons may yield some extra financial benefits, which may offset the required investments.

\section{Geothermal potential in stacked Triassic aquifer members}

Prospective Triassic geothermal aquifers are predominantly found in the Roer Valley Graben and West Netherlands Basin in the south and the Lower Saxony Basin in the northeast of the Netherlands (Fig. 7). Especially in the Roer Valley Graben, the sandstone layers are stacked, resulting in one thick sandstone layer. The Lower Volpriehausen Sandstone Member is also observed in other parts of the Netherlands, but is commonly too thin to warrant a satisfactory transmissivity.

The total geothermal energy potential of Triassic aquifers is considerable (Table 4): in the order of 300,000 PJ. These aquifers are especially of interest for spatial heating, roughly 61,000 PJ $\mathrm{PRH}$ is available from the Triassic aquifers alone (Table 4).

Triassic aquifers are commonly proposed as target reservoir. The Triassic aquifers in the WNB underlying the aquifers mentioned in the previous section may be even more suitable for district heating as higher temperatures can be expected. In the Roer Valley Graben the Triassic aquifers are at depths below $3000 \mathrm{~m}$ and may be used for spatial heating but are also of interest for industrial purposes as temperatures may even exceed $100{ }^{\circ} \mathrm{C}$. Especially in the central parts of the Roer Valley 


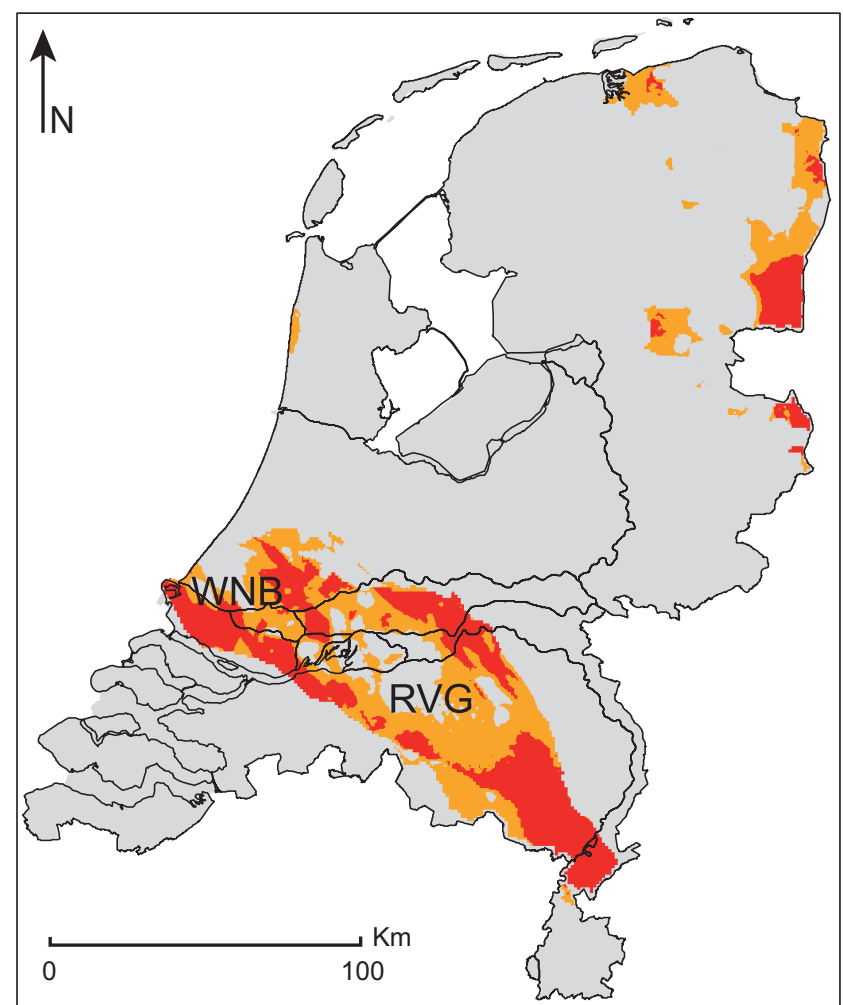

Geothermal potential greenhouse

Unknown

Possible potential

Good potential

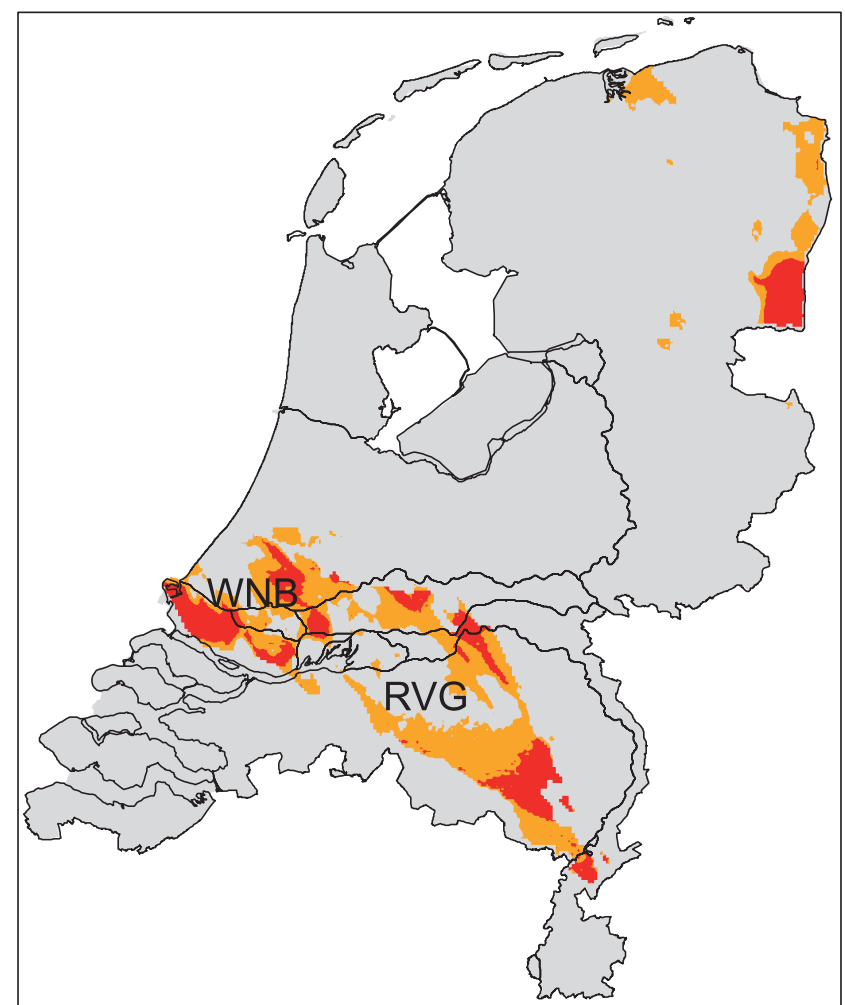

Geothermal potential spatial

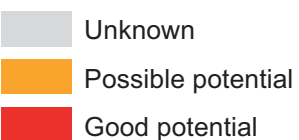

Fig. 7. Potential areas in the Lower Germanic Triassic Group. Potential areas for greenhouses on the right, for spatial heating on the left.

Graben aquifers are deeply buried. This may however have led to reduction of porosity and permeability due to compaction and diagenetic processes. Compared to the PRH and HIP the RH is therefore considerably lower (Table 4). Reservoir stimulation such as hydraulic fracturing can be considered for the areas where natural flow rates become too low. ThermoGIS only accounts for natural flow rates which reduces the $\mathrm{RH}$.

\section{Geothermal potential in Upper Rotliegend aquifers}

The Slochteren Formation is one of the most important gas reservoirs in the Netherlands. Many gas exploration wells have been drilled in this reservoir. The reservoir properties are therefore well known. Mainly in the north of the Netherlands large parts of the Slochteren Formation (Upper Rotliegend Group) have good to excellent reservoir properties for geothermal resource development for both greenhouse and spatial heating (Fig. 8). A drawback from a geothermal point of view is that many gas fields are present in this reservoir, which reduces the potential area for geothermal resources. Due to the areal extent, good reservoir properties and relative high temperatures the Slochteren Formation has a large share in the total HIP. The Slochteren Formation alone accounts for 409,000 PJ of available geothermal energy that can be used for both greenhouse and spatial heating (Table 4). By the end of August 2011 two wells have been drilled in the Koekoekspolder near Kampen. The target reservoir is the Slochteren Fm. and heat will be used for greenhouse heating. To date well performances are tested.

\section{Comparison predictions geothermal maps with recent exploration permits}

To date over 100 permit requests are submitted to the Ministry of Economic Affairs, Agriculture and Innovation. Figure 9 shows these permits on the potential geothermal map. This figure clearly shows that the potential geothermal areas predicted in ThermoGIS nicely line up with most permits that have been submitted. In a few cases exploration activities are outside the predicted potential areas for the following reasons: 1) the target reservoir is a local aquifer with moderate distribution or did not meet the requirements set in the selection procedure in the ThermoGIS project; 2) occasionally, heat extraction is proposed along fractured zones (the potential of fault and fracture zones is highly uncertain and difficult to assess and not considered in ThermoGIS); and 3) permits have been requested to explore at depths $>4000 \mathrm{~m}$ (e.g. EGS). 


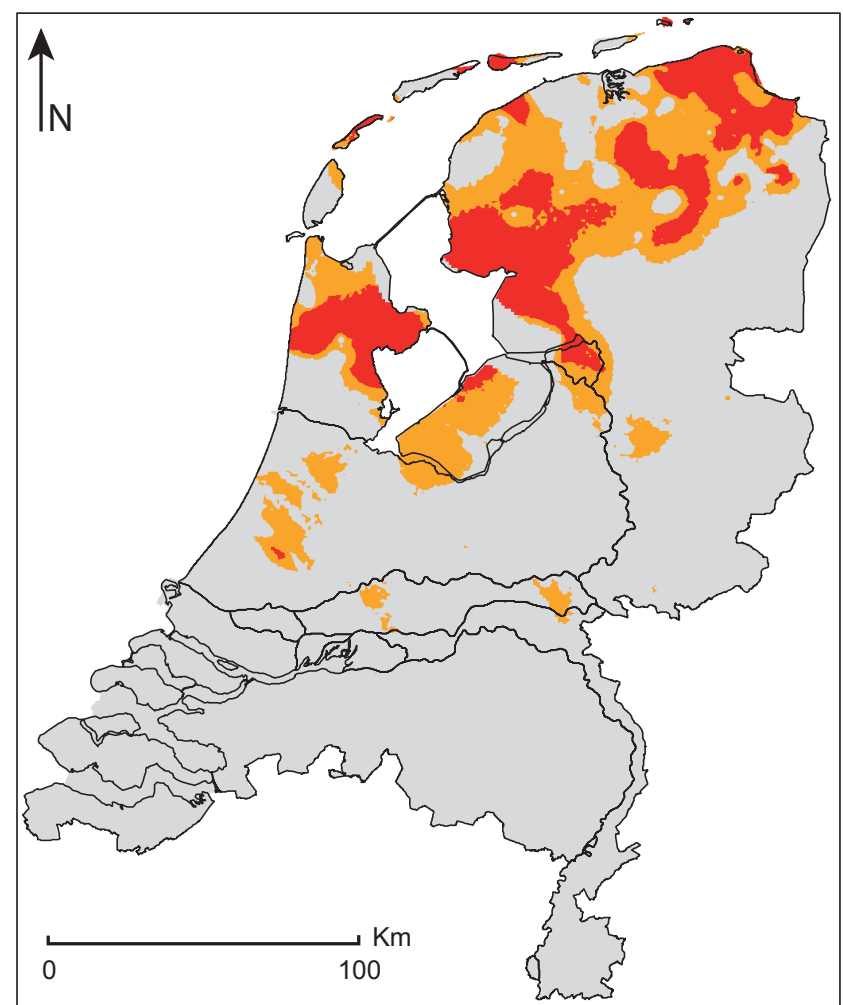

Geothermal potential greenhouse

Unknown

Possible potential

Good potential

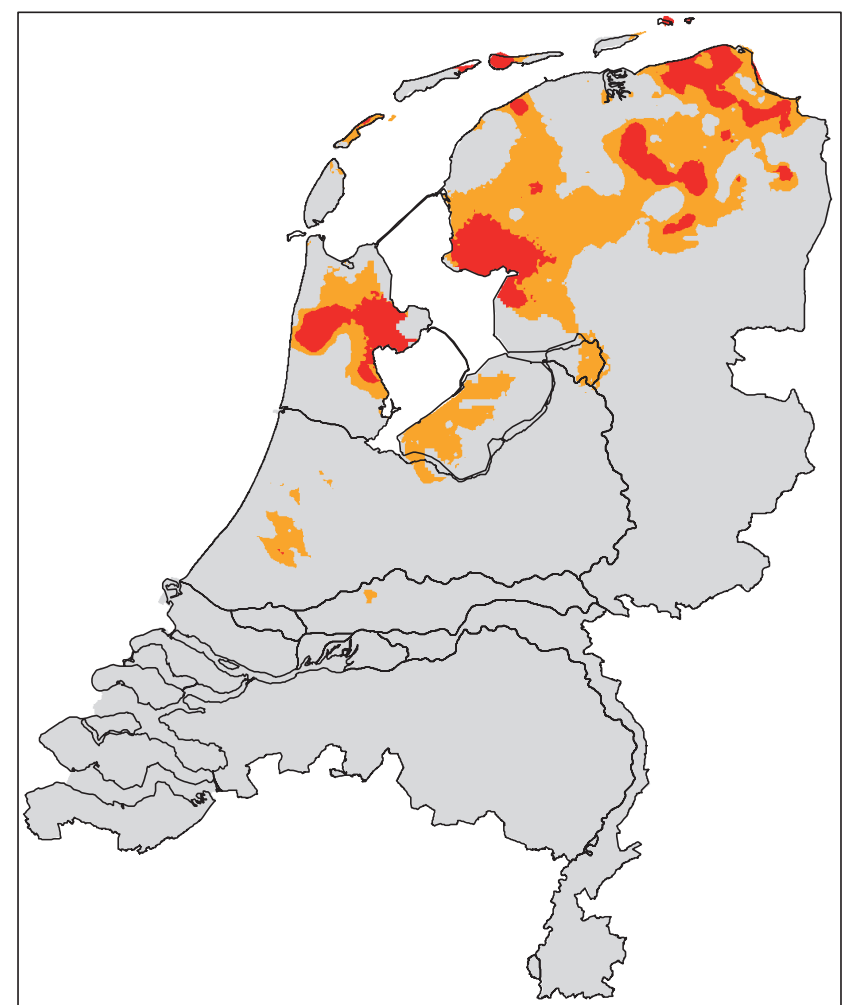

Geothermal potential spatial

Unknown

Possible potential

Good potential

Fig. 8. Potential low-enthalpy areas in the Upper Rotliegend Group. Potential areas for greenhouses on the right, for spatial heating on the left.

\section{Comparison with earlier studies}

Earlier estimates indicated that the HIP in the Netherlands was in the order of 90,000 PJ (Rijkers \& Van Doorn, 1997). The computation was based on an average thickness of the aquifer $(\geqslant 20 \mathrm{~m})$, a water temperature of at least $70^{\circ} \mathrm{C}$, an average difference between aquifer and surface temperature $\left(\Delta T \geqslant 40^{\circ} \mathrm{C}\right)$, the lateral extent of the reservoir and rough estimates in porosity, permeability and heat capacity. For these early estimates the boundary conditions were set in consultation with the EU. The assessment did not take into account techno-economic aspects to compute PRH and RH and no differentiation was made between greenhouses and spatial heating.

After detailed geological mapping and performance assessment in ThermoGIS the HIP is estimated more than 800,000 PJ, which is considerably more then the previous estimates. This is the result of: 1) a more accurate estimate of the thickness, depth and temperature of the aquifers; 2) the larger extent of the aquifers due to redefining the constraints; 3) inclusion of aquifers (like the Cenozoic sands and Jurassic Delft Sandstone $\mathrm{Mb}$.) that were not yet taken into account; and 4) improved reservoir property mapping (Pluymaekers et al., this issue). Furthermore, the assessment is improved by using a Monte
Carlo approach in stead of using average values. Differences between both studies are illustrated in Fig. 9 and Table 4.

\section{Interactive web-based information system}

In total over 400 maps have been created for the prospective aquifers, including structural information (depth, thickness) and properties such as permeability and resource potential. These have been incorporated in a publicly accessible webbased geographical information system, called ThermoGIS (www.thermogis.nl) in order to support the geothermal community in assessing the feasibility of a geothermal system at any location and to allow stakeholders to quickly assess geothermal energy potential on a national or regional scale. Based on stakeholder feedback it has been decided to present the information in a basic and expert information system, dedicated to users with and without subsurface expertise respectively.

\section{ThermoGIS Basic}

The basic edition of ThermoGIS, which can be navigated directly from the internet, provides power, application scale and potential maps as listed in Table 3. The aim of this basic edition is to give 


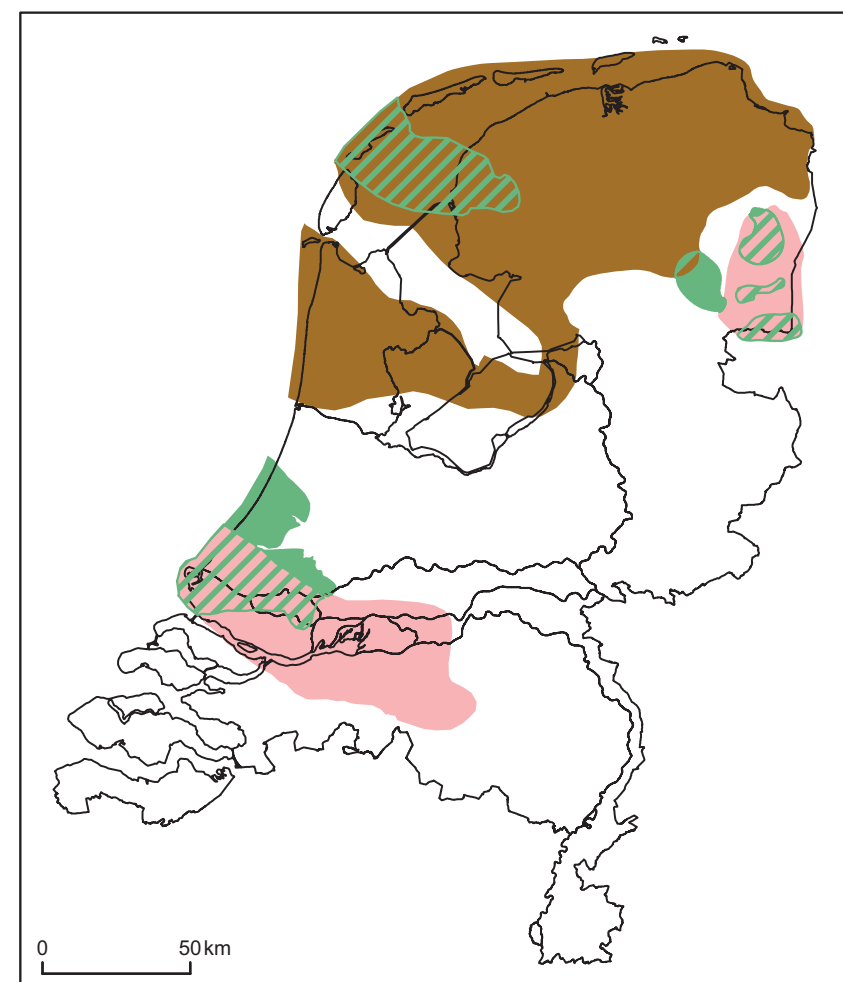

Rotliegend sandstones Triassic sandstones

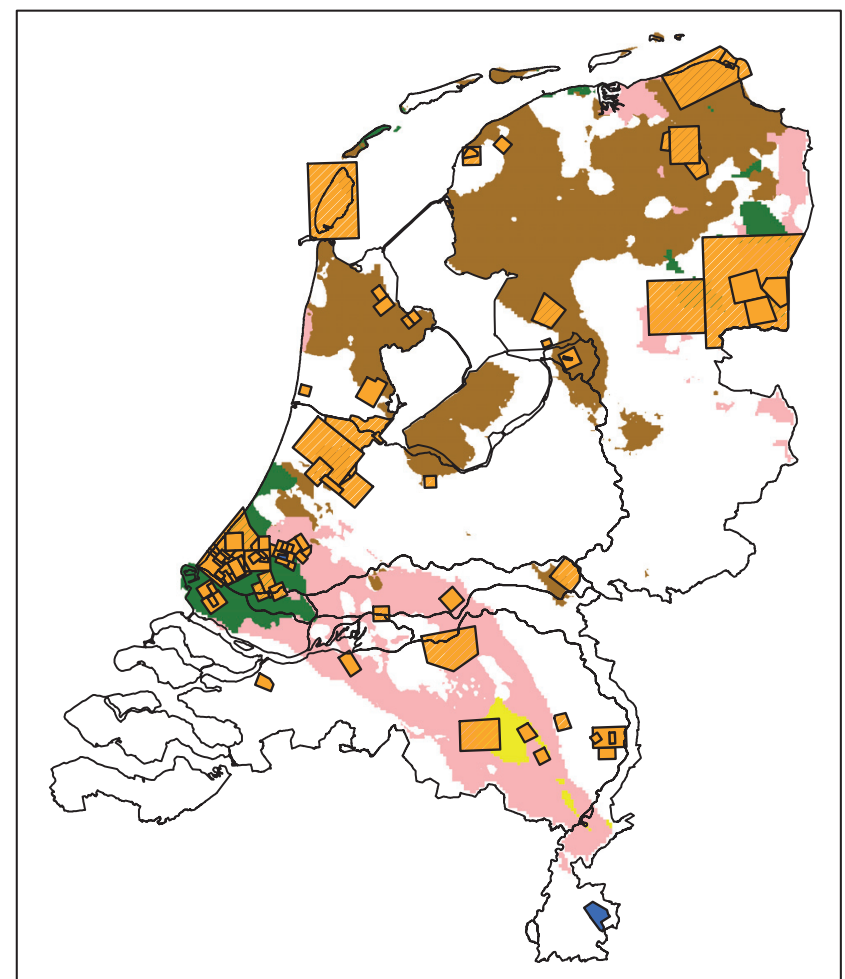

Applied exploration licence Exploration licence

Production licence

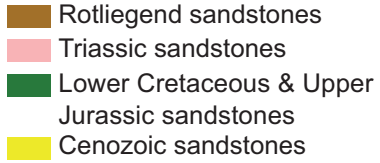

Cenozoic sandstones

Fig. 9. Past and new distribution overview maps of potential geothermal areas. Left: the potential area map from TNO-NITG (2004). Right: current potential map based on ThermoGIS.

a complete overview of the geothermal potential in the Netherlands. Furthermore, general maps of the recent geothermal wells, permits, greenhouse areas and oil \& gas fields can be switched on or off (Fig. 10). Easy accessibility and good look-and-feel were the key criteria in the development in order to appeal a broad audience.

\section{ThermoGIS Expert}

The expert edition contains all geological and performance maps for all (stacked) aquifers and includes a techno-economic performance assessment (TEPA)-tool called DoubletCalc (described by Van Wees et al., this issue) for site specific feasibility assessment. The expert edition can be downloaded from the ThermoGIS website. As the name already suggests the information will meet the requirements of experts.

In the expert edition all maps, as listed in Tables 2 and 3, can be selected. General maps of provinces, municipalities and well location can be ticked on and off. To zoom in to a specific location, coordinates or a zip code can be entered. Another feature is the ability to generate geological cross sections between any points on the map (Fig. 10). DoubletCalc can be launched after a location point is set on the map. After launching, the key geological parameters from the underlying geological regional maps will be loaded automatically in DoubletCalc. With this input the performance and economics can be simulated. Output indicators like performance, flow rate, COP, NPV and UTC will be displayed after the simulation run has finished. The results can be visualised via stochastic and probabilistic plots. Results will give a first quick scan of the geothermal potential for any location selected. It has to be stressed though that these results are based on regional geological interpretations. Therefore a more in-depth geological and economic feasibility study has to be carried out for future developments.

\section{Conclusion and discussion}

Renewed interest in geothermal energy, encouraged by climate change and rising oil prices, has led to a need for easy accessible data information systems and first order performance assessment tools. Through effective use of the large amount of publicly available deep subsurface data in the Netherlands these demands can be met. Geothermal property and resource mapping has been performed to designate prospective high permeable aquifers and to assess the amount of potential geothermal energy available. 

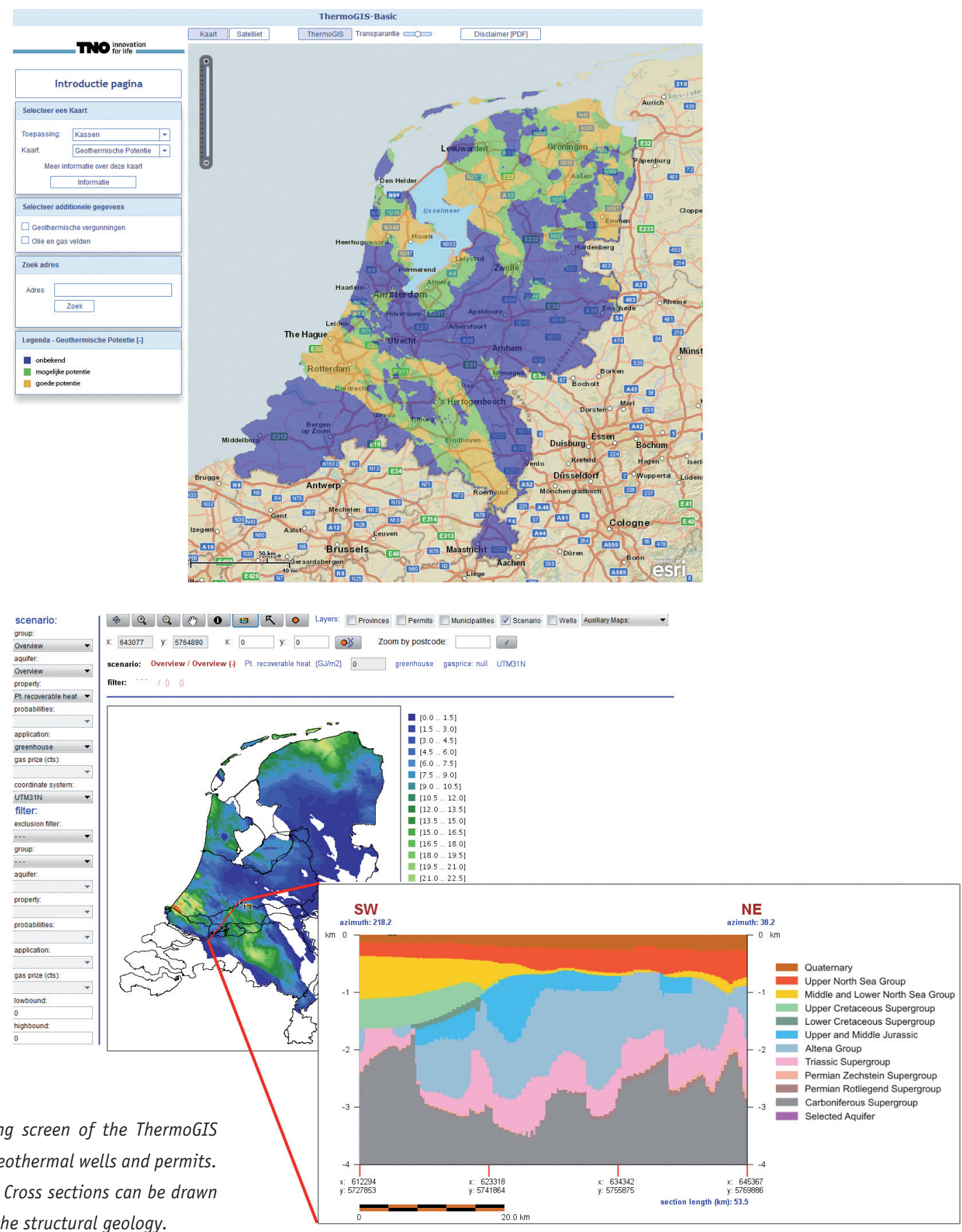

Fig. 10. Top panel: opening screen of the ThermoGIS basic application, showing geothermal wells and permits. Lower panel: expert version. Cross sections can be drawn to get an impression about the structural geology.

In the resource assessment analysis 14 lithostratigraphic units (clastic aquifers) have been mapped. For each unit the depth, thickness, porosity, permeability, temperature and transmissivity was mapped on a regional scale. Based on the property mapping, various performance indicator maps have been produced both for greenhouse and spatial heating. These include a) an indicative overview of the expected doublet power (MWth), which can be retrieved on an economic basis; $b$ ) an indication about the number of houses or hectares that can be heated utilising geothermal energy from a doublet; and c) a potential indicator map, which provides insight in subsurface suitability for specific applications. To obtain a nationwide overview of the resource potential in terms of geothermal energy a progressive filtering approach was used, from total heat content of the reservoirs (Heat In Place), the heat that can potentially be recovered (Potential Recovery Heat) up to energy maps taking into account a techno-economic performance evaluation (Recoverable Heat). Maps have been stacked for the Permian, Triassic, Jurassic/Lower Cretaceous and Cenozoic intervals, as individual reservoirs within e.g. the Triassic are often considered jointly in project development.

Results show that the HIP is approximately 820,000 PJ which is significantly more than previous estimates which reported figures around 90,000 PJ. This considerable increase in 
geothermal energy potential is the result of more accurate geological mapping of key reservoir properties and the development of state-of-the-art techno-economic performance assessment tools that facilitate Monte Carlo simulation and not taking into account any boundary conditions. From a geological point of view the potential geothermal area has increased considerably compared with earlier studies. Taking into account techno-economic aspects the $\mathrm{RH}$ is in the order of $85,000 \mathrm{PJ}$ which equals $70 \%$ of the ultimate recoverable gas of the Slochteren Gas field.

In total over 400 maps have been created for the prospective aquifers, which can be interactively assessed in the web-based information, called ThermoGIS (www.thermogis.nl). This application complements existing subsurface information systems available in the Netherlands and supports the geothermal community in assessing the feasibility of a geothermal system at any location and provides a non-expert insight in the geothermal energy potential on a national and regional scale. However, ThermoGIS has to be considered as a first order feasibility assessment, because site specific research is still essential to assess the geothermal potential accurately. Site specific studies (cf. Fig. 2) can significantly reduce uncertainty and increase probability of success to insurable levels of about $80 \%$ or more. Geological uncertainties in geothermal resource exploration and estimated potential are high. The main risk factor in geothermal resource development is the permeability (or transmissivity) of the aquifer. An unexpected low permeability will have dramatic financial consequences for a geothermal project as the required power cannot be realised.

\section{Acknowledgements}

We would like to thank H. Kombrink for reviewing our paper. Furthermore, we would like to acknowledge A. Lokhorst for his constructive review and sharing his experiences. The comments and suggestions of abovementioned reviewers have significantly contributed to the quality of our article.

\section{References}

Bonté, D., Van Wees, J.-D. \& Verweij, J.M., 2012. Subsurface temperature of the onshore Netherlands: new temperature dataset and modelling. Netherlands Journal of Geosciences 91-4: 491-515, this issue.

Muffler, L.J.P. \& Cataldi, R., 1978. Methods for Regional Assessment of Geothermal Resources. Geothermics 7: 53-89.

Pluymaekers, M.P.D., Kramers, L., Van Wees, J.-D., Kronimus, A., Nelskamp, S., Boxem, T. \& Bonté, D., 2012. Reservoir characterisation of aquifers for direct heat production: Methodology and screening of the potential reservoirs for the Netherlands. Netherlands Journal of Geosciences 91-4: 621-636, this issue.

Rijkers, R. \& Van Doorn, T.H.M., 1997. Atlas of geothermal resources in the European Community, the Netherlands. Netherlands Institute of Applied Geoscience TNO (Utrecht), Report number Report 97-24-A.
TNO-NITG, 2004. Geological Atlas of the Subsurface of the Netherlands - onshore. Netherlands Institute of Applied Geoscience TNO (Utrecht), 104 pp.

Van Wees, J.-D., Kronimus, A., Van Putten, M., Pluymaekers, M.P.D., Mijnlieff, H.F., Van Hooff, P., Obdam, A. \& Kramers, L., 2012. Geothermal aquifer performance assessment for direct heat production - Methodology and application to Rotliegend aquifers. Netherlands Journal of Geosciences 91-4: 651-665, this issue.

Warmteatlas Nederland, 2012. www.warmteatlas.nl. 